\title{
The Evolution of Teachers' Language Awareness
}

\author{
Stephen Andrews \\ University of Hong Kong, Pokfulam, Hong Kong
}

The paper focuses on the development of teacher thinking, specifically L2 teachers' subject-matter cognitions, i.e. their Teacher Language Awareness (TLA) (see e.g. Andrews 2001, 2003). The study examines the evolving TLA, as it relates to grammar, of three teachers, each a graduate with more than 10 years' experience of teaching English in Hong Kong secondary schools. All three teachers took part in a previous TLA study conducted in 1996-97 (see Andrews, 1999a), when they were in their early years of teaching and had received no professional training. In the present study, these three teachers' TLA and cognitions about grammar were investigated once more (in 2004). The aim of this follow-up study was to tell the story of each teacher's evolving TLA and grammar-related cognitions. In both phases of the research a mixed methods approach was adopted. Data from the two studies suggested that the teachers' TLA and grammar-related cognitions had altered very little. Their underlying beliefs about grammar pedagogy and the role of explicit grammar teaching, and their knowledge about grammar (as measured by a test of LA) seemed largely unchanged. The main difference between the three teachers was in their interaction with the context in which they worked.

Keywords: teacher language awareness, teacher cognition, teacher knowledge, knowledge about language

\section{Introduction}

The study reported in this paper is concerned with L2 teacher thinking, and in particular L2 teachers' cognitions regarding subject matter, i.e. their Teacher Language Awareness (TLA). The paper adopts Borg's (2003a) definition of teacher cognition: ' . . . the unobservable cognitive dimension of teaching - what teachers know, believe and think' (Borg, 2003a: 81). The specific focus of the study is on how far and in what ways teachers' subject-matter cognitions change over time, i.e. the evolution of TLA, with particular reference to grammar and the teaching of English as L2. Andrews (2003) contains a detailed discussion of the conceptualisation of TLA that underpins the research reported in this paper.

In the past 25 years, teacher thinking has become a major area of educational enquiry. Recent papers by Freeman (2002) and Borg (2003a, 2003b) review much of the relevant research. Freeman (2002) outlines the changing conceptualisations of teacher knowledge and teacher learning in the education literature, Borg (2003a) surveys the growing amount of research into L2 teacher cognition, while Borg (2003b) discusses studies that have focused on L1 and L2 teacher cognition specifically in relation to the teaching of grammar.

Among these studies of teacher thinking, there has been a significant amount of research focusing on the development of teachers' cognitions and practices (from Fuller \& Brown, 1975 to Burn et al., 2003). However, studies of teacher 
development have often concentrated on the development of novice teachers over a relatively limited period, for instance their year of initial teacher education (see e.g. Calderhead, 1987; Furlong \& Maynard, 1995). Such studies have also generally involved teachers of a range of subjects. Meanwhile, research focusing on teachers of a single subject (for instance, Zhu's 2003 study of the developing cognitions of teachers of English as L2) has tended for the most part to look broadly at various dimensions of pedagogical content knowledge (PCK), rather than a single component such as knowledge of subject matter.

In recent years, as Borg (2003a, 2003b) notes, there have been a number of studies of L2 teachers' cognitions, including several (e.g. Andrews, 1999a; Borg, 1998, 2005; Farrell, 1999; Johnson \& Goettsch, 2000) that have focused specifically on cognitions regarding subject matter. However, although these studies have often sought to gain insights into the sources of teachers' thinking in this domain, their data have generally been gathered at one stage of a teacher's career.

The present study, in contrast with those mentioned above, confines its attention to the developing cognitions of teachers of a single subject (English as L2), focuses specifically on one dimension of their thinking (their subject-matter cognitions, or TLA, with reference to grammar), and investigates these teachers' TLA at two stages of their careers: first, in 1996-97, and then again in 2004. It does so in order to learn more about the processes of development of L2 teachers' subject-matter cognitions, and to examine these processes in the light of what is known about teacher development more generally.

\section{Teacher Development and TLA}

Research on teacher development has revealed a number of characteristics that are potentially relevant to the present study:

- Teacher development is not a linear process by which all teachers progress in predictable ways. Berliner's (1995) five-stage model from novice teacher to expert acknowledges that teachers develop at different speeds and that only a minority advance through all the stages. Tsui (2003) makes a similar point when she distinguishes between expert teachers and experienced non-experts.

- Teacher development is a complex process, as underlined by Huberman's (1993) seminal study of the lives of 160 secondary school teachers. According to Huberman, the early years of teaching are characterised by elements of survival and discovery, followed (if the initial experiences have been positive) by a period of stabilisation marked by feelings of confidence, autonomy, pedagogical mastery, and a focus on the learner rather than the self. Thereafter, however, Huberman suggests that teachers' individual routes diverge, with some teachers moving on to periods of experimentation and diversification, while others enter a phase of self-doubt or reassessment. Then, in the later stages of teachers' careers, many enter a phase of serenity and affective distance, sometimes (though not necessarily) accompanied by conservatism, and followed (for most teachers) by a final phase characterised by different forms of 'disinvestment'.

- Teacher development is not always characterised by consistent progress. A number of studies (e.g. Field, 1979; Fuller, 1969) have suggested that teachers may move in and out of phases. Regression has been noted as a possibil- 
ity in professional development generally (Huberman, 1993:4), and Burn et al. (2003), for instance, found an element of regression in the development of the student-teachers whose thinking they studied over a one-year period. Meanwhile, Tsui (2003), in her study of expertise in teaching, argues that expert teachers can also regress by ceasing to be expert if, for any reason, they lose the characteristics of expertise.

- Research also indicates that the development of the individual teacher does not always occur consistently across all dimensions of teacher knowledge. Zhu (2003), for instance, found in her study of novice secondary EFL teachers that certain components of her subjects' pedagogical content knowledge (knowledge of students, knowledge of pedagogy and knowledge of self) developed more rapidly than others, among them knowledge of subject matter. Tsui (2003) also points out the unevenness of teacher development, arguing that expertise in teaching is best seen as applying to certain dimensions of the work rather than all. She suggests that teaching is such a complex and ill-defined profession that it might be more meaningful to talk about expertise in areas of specialisation (i.e. multiple expertise) rather than to use general terms like expert teacher.

The present study focuses on one such area of specialisation in the L2 teacher's work: subject-matter cognitions (TLA) as they relate to grammar. The study sets out to examine whether the evolution of TLA exhibits similar features to those noted above in relation to the processes of teacher development more generally.

\section{Background to the Study}

In 1996-97 a study was conducted of the TLA (as it relates to grammar) of Hong Kong secondary school teachers of English (see e.g. Andrews, 1999a, $1999 \mathrm{~b}, 2001$ ). The subjects were untrained graduates (in many cases NOT of English). All of them were applicants for entry to the two-year part-time initial professional training programme for serving teachers, the Post-graduate Certificate in Education (PCEd), offered by the University of Hong Kong (HKU). Data were gathered from the entire set of PCEd P/T English Major applicants in spring 1996. All 187 applicants took a battery of tests (including a Language Awareness Test); 170 of them also completed a questionnaire.

Only 17 of those 170 subjects were subsequently selected for an in-depth study of their TLA, which took place during their first year on the PCEd programme (1996-97). The process of sampling for the in-depth study was purposive (focusing on teachers who were all Hong Kong Chinese and who were otherwise broadly representative of trends within the larger sample). At the same time, practical considerations also affected the sampling. The in-depth study necessarily involved only subjects who were accepted for admission to the PCEd, which immediately reduced the pool to 63 . That pool then became 37 , because 20 of the 63 admitted to the PCEd had been on the waiting list from the previous year (and had therefore not taken the battery of tests) while a further six were nativespeakers of English. Of those admitted to the PCEd, 21 were invited to participate in the study (with the selection taking into account such factors as performance on the test battery, gender, location of tertiary education, and relevance of degree), and four declined. During the in-depth study of the 17 who agreed to 
take part, questionnaires, semi-structured interviews, video-taped classroom observations, and grammar-related tasks were used to collect data shedding light on the nature of TLA and its impact on pedagogical practice.

In late 2003, an invitation was sent to all 17 participants in the 1996-97 in-depth study, asking if they would be willing to take part in a follow-up study of their TLA. Given the demands of participation in the earlier study, it was anticipated that a substantial proportion of the original subjects would not be willing to be involved in the follow-up. As the intention was to conduct only a small-scale investigation at this stage, the hope in issuing the invitation was that there would be up to four willing participants, offering some variety of background, gender and test performance. In the event, three of the original subjects responded positively: Maggie, Eva, and Tony (all pseudonyms).

\section{Research Questions}

This follow-up study was designed to address the following research questions:

(1) What is the present level (as measured by a test) of each teacher's subject-matter knowledge as it relates to grammar?

(2) What are each teacher's cognitions about grammar and grammar pedagogy?

(3) In what ways (if any) have each teacher's grammar-related cognitions and practices evolved in the past seven to eight years?

(4) How does each teacher account for his/her subject-matter cognitions and pedagogical practices relating to grammar, and for any changes in the past seven to eight years?

\section{Methodology}

In order to address these questions, a mixed methods approach was adopted. The overall approach was mainly qualitative, drawing on interviews, classroom observation and teacher narrative, but quantitative data (in the form of test scores) informed the discussion of the teachers' subject-matter knowledge, past and present (questions 1 and 3). The aim was to tell the story of each teacher's evolving TLA and cognitions about grammar.

In contrast with the 1996-97 study, the construction of each story was a process of collaboration between teacher and researcher, beginning with the teacher's own 'storying' of his/her experiences with grammar as learner and teacher. As Golombek and Johnson (2004) note, ' . . . the use of narrative has emerged as the predominant means of getting at what teachers know, what they do with what they know and the sociocultural contexts within which they teach and learn to teach' (Golombek \& Johnson, 2004: 308). Each of the selected methods contributed in a different way to the understanding of the teachers' stories, with the multiple sources of data for each case providing the opportunity for triangulation.

The following data contributed to the understanding of each teacher's story:

(1) Performance on a test of Language Awareness (in 2004, and also in 1996). The LA test used in the 2004 data collection (see Andrews \& McNeill, 2005 
for details) was an expanded version of the 1996 test (based on Alderson, Clapham and Steel's test [see e.g. Alderson et al., 1996, 1997], which in turn drew on Bloor [1986]). Common to both versions of the test was a 60-item grammar component, made up of four tasks (see Appendix 1 for examples of three of the tasks).

(2) Video-taped lesson data (in both 2004 and 1996-1997).

(3) Interview data (again in 2004 and also 1996-97).

(4) An essay on the role of grammar in English language teaching (1996).

(5) A personal narrative from each participant in which they described their experiences with English grammar, as a learner and as a teacher (2004) (Appendix 2 contains the narrative specifications. The original intention was for the narratives to be written, as the specifications suggest. However, two of the participants preferred to tell their stories orally. They therefore submitted audio-taped narratives, which were later transcribed).

Based on an initial analysis of these data, past and present, the researcher wrote a narrative about each participant. To enhance the trustworthiness of the narratives, each participant was invited to comment on his/ her narrative and to suggest amendments, as necessary. The majority of the proposed amendments related to errors of fact. All of them were incorporated in the final versions of the narratives.

\section{The Participants}

As noted above, three teachers took part in this longitudinal study: Maggie, Eva and Tony. Maggie is now 32, and has been teaching English for 10 years. Eva is 35 , and has been teaching for 12 years. Tony, the oldest, is now 39 . He has been teaching for 11 years.

During Maggie's 10-year career, she has taught in two Hong Kong secondary schools: a co-educational school in the New Territories (for eight years) and an English-medium (EMI) girls' school on Hong Kong Island (for the past two years). When she started teaching, she had no relevant qualifications at all: her degree (from the United States) was in Business Studies, and she had no teacher training. Since joining the profession, however, Maggie has undertaken a variety of studies. After she had been teaching for a couple of years, she joined the HKU part-time PCEd programme ('because I could get a salary rise . . ' Narrative, May 2004). Then, in 1999, she began studying for a Master's degree in Applied Linguistics, and she is currently working on a PhD.

Eva's first teaching post was in a Chinese-medium (CMI) Girls' School in Kowloon. Having taught there for one year, she left the profession for two years. Then, in 1993, she resumed her teaching career, taking a post at a New Territories co-educational school that was notionally EMI, where she stayed for six years. Her present post is in a co-educational CMI school, again in the New Territories, which she joined when it first opened, with just F1 and F4, five years ago. She is the English Panel Chairperson (i.e. Head of Department). Eva began her teaching career with a relevant first degree (in English from the Hong Kong Baptist University), but without professional training. She began studying part-time for her PCEd in 1996-97, by which time she had already obtained a Master's degree 
in Language Studies from the Baptist University. She is currently working towards an EdD, which is scheduled for completion in 2007.

When Tony first started teaching, he took up short-term posts in two schools. He was then offered a position at a CMI school in the New Territories. Ten years later he is still in the same school. Like Maggie, Tony has a non-relevant first degree from a North American university, in his case a BA in Social Science from the University of Calgary. Unlike Maggie, however, Tony took some Linguistics courses as part of his degree studies. Tony had no professional training when he started teaching. However, he obtained a part-time PCEd from HKU in 1998, and he has since completed a BEd at the Open University of Hong Kong (which offered the incentive of exemption from the otherwise mandatory Language Proficiency Assessment for Teachers, or LPAT test) and taken an in-service refresher course at the Hong Kong Institute of Education.

\section{Results 1: The evolution of subject-matter knowledge as it relates to grammar}

This first results section focuses on what the data reveal about the present level of these teachers' subject-matter knowledge as it relates to grammar (research question 1), and the extent to which their knowledge has evolved since 1996. Table 1 gives the details of each participant's 1996 and 2004 performance on those components of the LA test common to both versions. Their scores on the four grammar-related tasks are presented in order of difficulty, starting with Correction of Errors (the easiest task according to the scores of most takers of the test). The bottom row gives the total scores for the grammar component of the test. The right-hand column provides, for the sake of comparison, the mean performance of the 187 subjects who took the LA test in 1996, including these three.

In any consideration of these results, the limitations of the test must, of course, be acknowledged. The grammar component comprises only 60 items, and three of the four tasks place heavy emphasis on the knowledge of particular types of metalanguage. When comparing performance across the two administrations of the test, it should also be noted that these took place under rather different circumstances. In 1996, the 187 subjects took the test in a large examination hall, with the competition for a university place acting as an incentive for them to perform well. In 2004, by contrast, each of the teachers took the test in his/her own school, without any extrinsic motivation.

Table 1 Performance on the grammar component of the LA test

\begin{tabular}{||l|l|l|c|c|c|c|c||}
\hline \multirow{2}{*}{} & \multicolumn{2}{|c|}{ Maggie } & \multicolumn{2}{c|}{ Eva } & \multicolumn{2}{c|}{ Tony } & $\begin{array}{c}\text { Mean scores } \\
\text { (n = 187) from } \\
\text { Andrews } \\
(1999 a)\end{array}$ \\
\cline { 2 - 10 } & $\mathbf{1 9 9 6}$ & $\mathbf{2 0 0 4}$ & $\mathbf{1 9 9 6}$ & $\mathbf{2 0 0 4}$ & $\mathbf{1 9 9 6}$ & $\mathbf{2 0 0 4}$ & $\mathbf{1 9 9 6}$ \\
\hline Correction of errors & 87 & 87 & 93 & 100 & 87 & 73 & 80.6 \\
\hline Recognition of metalanguage & 83 & 83 & 89 & 83 & 83 & 89 & 75.1 \\
\hline Production of metalanguage & 67 & 75 & 83 & 67 & 79 & 75 & 63.2 \\
\hline Explanation of errors & 30 & 43 & 60 & 63 & 47 & 53 & 38.9 \\
\hline Total & 67.5 & 72.5 & 82 & 81 & 74 & 73 & 65 \\
\hline \hline
\end{tabular}


Keeping those limitations in mind, there are nevertheless interesting and revealing patterns of performance among the results which are worthy of comment. The most noteworthy feature is that, as indicated by the test scores, these three teachers' subject-matter knowledge as it relates to grammar appears to have changed remarkably little. In comparing performance in this way, it might be argued that all three participants scored above the mean when they first took the test, and therefore there was limited scope for improvement. Eva, for instance, scored $82 \%$ in the 1996 administration. However, given the elementary nature of all the grammar items in the test, it does not seem unreasonable to have anticipated some improvement from all of them, including Eva. Tony and Eva's total 2004 scores are in fact almost exactly the same as eight years previously. Both performed better in two components and worse in the other two, with their total score 1\% lower than before. Maggie's total shows a slight improvement: in two components she scored exactly the same as in 1996, while in the other two she scored a little higher, giving her a $5 \%$ improvement overall. However, this cannot really be said to represent a marked change. All three performed better than they had before in the most challenging part of the test, the explanation of grammatical errors, although that improvement was only slight in the case of Tony and Eva.

Given that they have been teaching English full-time for eight years since they first took the test, it seems at first sight surprising that their knowledge about grammar, at least as measured by the LA test, has remained so stable, particularly since all three of them have engaged in various forms of continuing professional development (CPD) during this time, as noted above. However, it is important to recall that none of their further studies have focused specifically on grammar, which may possibly help to explain the absence of substantial change in their test performance. That is certainly how Tony, for instance, views matters. Without knowing his test scores, he reflected about himself:

My knowledge of grammar hasn't increased in these days. Because I didn't do any grammar courses. I didn't study for grammar, except when I was preparing my lessons. Most of the courses I did were about education, about the teaching of language in Hong Kong, stuff like that. I didn't do anything specifically about grammar. (Interview, May 2004)

Nevertheless, it is interesting to note the apparent lack of any positive impact from his eight years of grammar lesson preparation.

\section{Results 2: Evolving cognitions about grammar and grammar pedagogy}

The second results section focuses on the evolution of the three teachers' beliefs and thinking about grammar and their own grammar pedagogy, as reflected in the narratives written by the researcher. Those narratives drew on the full range of the data gathered during the two phases of the study, but particularly on the interview and narrative data. The observation data, snapshots of the participants' classroom behaviour at two stages of their careers, are not cited in any of the abbreviated narratives that follow. However, those data were crucial in providing evidence of the extent to which each teacher's practices were consistent with his/her description of those practices, and they allowed the interpretations in the narratives to be made with greater confidence. 
The basic organisational structure of the full narratives is chronological, as is the case with the abbreviated narratives that follow. Each full narrative begins with a brief set of factual statements about the teacher's professional experience and his/her qualifications and ongoing professional development. In the present paper that information was provided in an earlier section and is not repeated here. The narrative then describes the individual's grammar-related experiences, first as a learner of English and then as a teacher. However, although the narratives describe each teacher's experiences chronologically, the discussion of a particular phase in an individual's career does not necessarily draw solely on data collected during that phase. For instance, some of the data informing the comments on cognitions and practices in 1996-97 were gathered at that time, while others were collected more recently, taking the form of reflections from a distance of some years which contextualised those earlier cognitions and practices in relation to developments since.

The key elements of each story are presented teacher by teacher, starting with Maggie.

\section{Maggie}

When she was first interviewed in 1996, Maggie described herself as 'not much of a grammar person' [Interview, Autumn 1996]. She attributed this at least in part to her own background, which involved learning English largely through immersion (at an EMI secondary school, through extensive exposure outside class, and then via her tertiary education in the US). Indeed, her only experience of formal grammar teaching as a learner was with her F4 teacher, and it confirmed the view she had already formed that explicit teaching of grammar was both boring and pointless:

It was extremely boring to take grammar lessons. I didn't quite understand her explanation, or maybe I didn't pay attention. The grammar book became a big doodle book. I didn't, and still don't, believe one can really learn how to use grammar this way. I mean one can learn grammar, but not how to use it. There are too many rules and exceptions; I simply couldn't remember them all. (Narrative, May 2004)

At the start of her teaching career, Maggie found that her lack of interest in, or knowledge about grammar made her very much the 'odd one out':

Teachers around me seemed to have a big vocabulary for grammar, especially my panel head. He couldn't read or write, but he was very good at throwing those grammatical terms every time we had a meeting. I had to read some grammar text books before I actually knew what they were talking about. (Narrative, May 2004)

This feeling continued when Maggie began her PCEd course. She again felt that she was different from her peers, because she lacked what she described as 'literacy in grammar':

Sitting in the PCEd class was a nightmare. The classmates were all grammarians. I had absolutely no idea what they were talking about. (Narrative, May 2004) 
Despite her lack of interest and confidence, however, Maggie had no choice but to teach grammar in her first school, partly because of the dictates of the public examination, and partly because of the requirements of the Panel Chair:

I don't have much choice in ... what things we have to do in class because the panel chairman force us to do grammar. (Interview, Autumn 1996)

From the beginning of her career, Maggie had a strong instinctive commitment to CLT. She could nevertheless see a certain logic in focusing on grammar in the school where she started teaching, because of the expectations of her students, which seemed to be markedly different from those of Maggie and her classmates when they were at school:

When I was studying, we don't have grammar lesson at all ... We just sort of learned it, through I don't know reading, speaking or listening. For some reason it did seem simple to learn when I was young ... But when I look at my students, they have no idea how to get those things. They have to go formula type. They have to ... OK, if you have such situation, then you use -ing form. (Interview, Autumn 1996)

However, Maggie's general view of explicit grammar teaching was negative, because she felt that it had little impact on students' interlanguage:

When this is like at least their tenth year of learning English, they already have their own whole set of language system, their own version of English. Or their own version of Chinese. So it's like we have to wipe out a little part of what they have and put in my version of it. Well, which I hope it should be the right one, the more appropriate one. So it's difficult sometimes ... they're refusing to erase that part of their system, or any add-on. (Interview, Autumn 1996)

Maggie's MA studies in Applied Linguistics, which she began in 1999 (because she 'was bored' [Narrative, May 2004]), influenced her in various ways, including increasing her confidence in dealing with language, at least at text level:

The course also got me to become more sensitive to the language itself. In a way, this helps a lot. When I was teaching, I found myself doing more textual analysis with the students, and because I understood it more, it was easier for me to communicate the knowledge with the students. (Narrative, May 2004)

However, having completed her MA in 2001, Maggie began to experience a growing sense of frustration in her teaching context. Worsening discipline problems in her school made it impossible for her to introduce innovative ideas about language and language teaching that she had picked up from her course. So, in 2002, Maggie took the opportunity to move to a more academic (EMI) girls' school, similar to the one in which she herself had studied.

In her new school Maggie has managed to secure a timetable which minimises the need for explicit grammar teaching: F5 and F7 English Language, F5 and F6 English Literature, and F1 Reading. Maggie stills feels obliged to deal with grammar to some extent in her F5 and F7 classes, because of the school's pressure on 
public examination results, and because of student and parental expectations of examination preparation at that level. However, her opinions about the value of explicit grammar teaching have not changed in the course of her career, as the following remark reveals:

I really don't believe in the merits of teaching grammar just for the sake of teaching. It is like grammar teaching has to be done because it is 'grammar'. I didn't learn it that way, so I really don't believe it could be taught that way. (Narrative, May 2004)

When she is called upon to explain discrete grammar items, Maggie acknowledges that she still lacks confidence in her own abilities, even after 10 years of teaching:

Basically I know how to use it, but ... when I try to explain it ... it's still like really messy, unless I really prepare for it ... and if they just like ask me ... it's really embarrassing as a teacher ... But I really am not interested in grammar, and every time I open a book, it's like when I was a kid. I just get really bored. (Interview, 25 February 2004)

As she says herself, although her understandings of language may have broadened and become more sophisticated, largely as a result of her postgraduate studies, her views and feelings about grammar and grammar teaching have changed very little throughout her career:

Ten years down the road I'm still that same person pretty much. I don't really like grammar. I don't really like teaching grammar. (Interview, 17 June 2004)

\section{Eva}

Eva's story is one of tension between her own low personal interest in grammar on the one hand, and the sense of obligation she has towards the teaching of grammar on the other. Eva readily acknowledges that she herself is a non-grammar person. However, she also recognises the importance of grammar knowledge as a foundation, particularly for students with limited exposure to English outside the classroom.

Like Maggie, Eva learnt grammar implicitly, as a student at an EMI secondary school in Hong Kong: ' . . we weren't aware of what the rules are, and the teachers didn't care to explain the rules to us' (Narrative, May 2004). At university, as an undergraduate majoring in English, Eva studied grammar more systematically, but her beliefs in the limited practical value of knowledge about grammar did not change fundamentally. Based on her own experience, she felt that being good at English was largely unrelated to grammar.

When she first began teaching, Eva was expected to teach grammar. This was challenging for her, despite her subject-relevant university studies, partly because grammar did not interest her greatly. She nevertheless found that now she was a teacher it was easier to see the usefulness of explicitly teaching grammar, because grammar gave a focus to the lesson:

For students they need something to get hold of to let them know that ... for English... it's not a matter of luck or chance to get something correct or not. 
They need some rules to reassure themselves that they get something from the lessons. (Interview, Autumn 1996)

At the start of her career, Eva employed a very traditional approach: 'The first one or two years of my teaching my lesson is always talk and chalk' (Interview, Autumn 1996). By 1996, however, Eva's approach to grammar pedagogy had evolved to one involving activities, with grammar as the framework. Eva felt more comfortable with such an approach. She expressed the belief that grammar teaching need not be boring:

Grammar exercises would not be a boring task for students as long as they are supplemented by interesting games and teaching strategies. (Essay, March 1996)

Eva persevered with this sort of approach, although in her self-critical reflections she commented that the students did not always respond as she would have wished:

They'll find that grammar is very boring, and they did find that, and they told me ... I'm always dissatisfied with my grammar lessons ... because they did not participate well ... I'm discouraged to use activities in grammar lessons because first of all they're hostile to some of the students and then they're not sincere ... they just try the easy way out ... and that's not what I want, but I can't force them, right? (Interview, Autumn 1996)

By 1999 Eva felt that she was ready for a new career challenge. She therefore accepted a Panel Head position in a new and less academic school, which had only F1 and F4 in its first year. Eva feels that the role of Panel Head has given her increased confidence, but she is also aware of the responsibility:

There are a lot of things I have to take care of. Because even though my Principal said that I'm not teaching all the students, how I make other teachers to teach is my responsibility. (Interview, 14 April 2004)

Eva's preferred approach would be to provide a language-rich environment for the students, so that they could learn language in the way she did. However, she acknowledges that this is not possible, because of the context in which she works, with student discipline and attitude problems. She has therefore had to adopt practices that are out of alignment with her preferences: 'My theory may be contradictory to what I'm doing, because the school won't provide enough language environment to the students' (Interview, 14 April 2004).

Because of the environmental conditions, Eva finds herself obliged to give the students rules, formulae, and grammar terms: 'Given so bad an environment, I have to use some rules to give them a sense of having learned something that they can apply' (Interview, 14 April 2004).

Eva's colleagues in her present school are much more enthusiastic advocates of explicit grammar teaching than Eva herself. Rather than imposing her own views as Panel Head, she has to some extent accommodated her colleagues' expectations, for instance by allowing the choice of textbooks to be democratic, even though the teaching approach in the chosen books is not to her taste:

I was sort of forced to use grammar jargons in my teaching because the 
exercises they set, the textbooks and grammar books they chose were full of such terms. I doubt the need to present grammar in that way, but I kept an open view, to try out. (Narrative, May 2004)

However, Eva still tries to employ an approach in which grammar is taught via examples, games and activities, with a focus on message and meaning rather than just form, and providing as many opportunities as possible for students to use the language. She perseveres with this approach even though it is not always successful, or what students want: 'I'll tend to use examples more often than giving them rules. But they want rules' (Interview, 14 April 2004).

Rather than compromising further, and ending up teaching as her colleagues do, Eva has now decided that she is going to use her position as Panel Head to assign herself more and more teaching in the highest forms (F6 and F7): 'I will move more and more into my own way' (Interview, 11 June 2004).

She feels that this strategy offers her the best chance of being able to stick to her principles, because the senior form students are most likely to be capable of responding to her approach:

For the upper forms, the mentality would tell them they should not do exercises like drilling grammar rules. They should do more contextualised, less controlled exercises. (Interview, 11 June 2004)

\section{Tony}

Tony's story is a little different from the two that preceded it, in that it illustrates how teachers' thinking and practice may be influenced by events in their personal lives at least as much as by professional considerations.

When Tony started teaching, he had limited subject-matter knowledge and no pedagogical training. At that stage his ideas about teaching grammar: ' . . mostly came from the way I was taught in secondary school. I was modelling my English teacher at that time' (Interview, 27 May 2004). His approach focused on the transmission of grammar rules, followed by mechanical practice exercises.

This approach was not entirely consistent with Tony's own views of the best way to acquire languages: ' . . if we teach grammar, we just teach grammar only, then . . . we can't help the students . . to learn English' (Interview, November 1996). He taught like this because he was following instructions:

I just follow ... what I was told to do ... If I can decide what I can teach, I will give them passages to read and just let them recognise grammar items. (Interview, November 1996)

He also found that this formulaic rule-driven approach to the teaching of grammar was popular with students, even though he personally doubted its value:

... to them it's quite important, because there's something they can study ... the grammar ... To them it's quite ... helpful cos they can study for their exams. But to me, I don't think it's enough to teach them so many grammar items. (Interview, November 2004)

However, the deficiencies of this rule-driven approach became increasingly apparent to Tony, partly because of the response of the students: 
They found that grammar was very difficult. It's a very difficult thing and then it's very boring. And I found that it's quite difficult for me to teach them, too. It's kind of boring just to tell them the forms and ask them to do exercises. So I started to question whether teaching grammar is the right way to help students to learn English. (Narrative, April 2004)

As a result of such reflections, as Tony's awareness of the available options increased, he modified his approach, trying to reduce the focus on explicit grammar teaching and instead introducing tasks, tailored to a level that would suit the students in the school:

I tried to teach less grammar. I used the lessons to ask them to read newspapers ... and I encouraged students to borrow books from the library, and read story-books when they have spare time. And I started to organize a lot of activities during the lessons and tried to make students use the language forms in a more meaningful way. (Narrative, April 2004)

These changes met with mixed success, however. There was initial interest among the students, but Tony found it very tiring to prepare suitable tasks, and he also found it difficult to implement a more holistic, task-based approach to language teaching in a school where the assessment system still emphasised discrete-point testing of language items. He has therefore reverted to a more grammar-based approach:

... I was exhausted. And I had no time to prepare some more tasks. So I just went back to the textbook, the grammar textbook, doing exercises. (Interview, 27 May 2004)

I've been forced to change. I have to teach grammar, otherwise my students will fail. I will lose my job. It's a pity, right? (Interview, March 2004)

Tony's re-adoption of a more grammar-focused approach to teaching has also taken place in the aftermath of an event in his life that has had a particularly significant impact on his development as a teacher. In May 2003, he was diagnosed as suffering from depression, and was obliged to take a long period of sick leave:

... I think it [my depression] is related to how I see myself. I always demand myself to do a lot of things, to try to be idealistic all the time, but that's not the reality. So I don't think it's the frustrations that I face in teaching that make me have the depression. Of course, it had some contributions ... I mean the workload, the kind of frustrations when I see the HKCEE results, and the pressure from the Principal . . . all these will contribute to the pressure. But the underlying most important thing is not all these factors . . . it's how I see myself. (Interview, 27 May 2004)

Tony thought about moving to another school during his sick leave, and was tempted by an offer elsewhere. But worries about the salary and the likelihood that the pressures would be just as great led him to stay in his present job, and to reappraise his whole approach to teaching:

I become more relaxed, and teach what I was told to do. I do what I was told to do, teaching grammar, and helping students to get a pass in tests. (Interview, March 2004) 
Tony's has modified his teaching approach for very pragmatic reasons:

The school will evaluate me in terms of what I have taught to the students. $\mathrm{OK}$, if their results are not good enough, they will look at what I have taught. If I try to make something not according to their syllabus and everything screws up, that will be my responsibility. But if I have done what I was told to do, and their results are not good, then it's probably not my responsibility. So I was forced to change. (Interview, 27 May 2004)

Tony's understandings of grammar have broadened considerably during the past eight years. He now pays attention in his teaching to aspects of what he calls 'genre grammar', and he has more fully formed views of where grammar might fit into a more 'meaning-focused' task-based approach. However, his underlying views of grammar and its role in teaching have not changed fundamentally: he still sees the need for students to know 'the basics', supported by as much exposure to the language as possible.

Although Tony has now reverted to an explicitly form-focused approach, his handling of grammar in the classroom has evolved to some extent since his first years of teaching. He still describes his approach as 'chalk and talk', but he now gives the students a chance to talk as well, and pushes them to take responsibility for their learning:

In the past I do all the talking all the time. I make sentences on the blackboard and write down the other things. But now I will talk, give them the forms plus examples, and then I will ask them to make sentences, ask them to stand up, and give the sentence orally. That's the main difference. They have their turn to participate. They can use the language forms. They can try it out. (Interview, 27 May 2004)

\section{Conclusions}

On the evidence of this small-scale study, the evolution of these teachers' subject-matter cognitions (their TLA) appears to reflect many of the characteristics noted in the studies of teacher professional development referred to previously, in particular the complex variability of teacher development mid-career identified in Huberman's (1993) study. As these three emerge from 'stabilization', that phase which the vast majority of teachers go through when ' . . a sense of minimal consolidation is attained' (Huberman, 1993: 6), they are clearly doing so in rather different ways.

Eva, for example, appears to be in a dynamic phase, during which she has changed school and taken on new professional challenges as English Panel Head. In coming to terms increasingly confidently with that role, she has experimented with different ways of adjusting to the characteristics of the new teaching context and the attitudes of her new colleagues without significantly compromising her fundamental beliefs about grammar and grammar pedagogy. Meanwhile, her EdD studies, which she has embarked on in this dynamic phase, seem to be instrumentally motivated, with the aim of strengthening her school-based career prospects.

Maggie is in some ways in a similar phase of 'experimentation' and 'diversification'. However, Maggie's professional development, beginning with a Master's 
degree and continuing into $\mathrm{PhD}$ study, seems to be motivated by interest and a personal quest for understanding rather than a desire for career advancement within the school sector. In contrast with Eva, Maggie's change of school seems to have been prompted by 'push' factors associated with the previous school and its location rather than by the 'pull' factors of the new school or career ambition. Nevertheless, the move has provided various opportunities for experimentation, while enabling Maggie to limit the specific challenges to her ideas and understandings about grammar.

Tony's development is the most markedly different. Unlike Maggie and Eva, Tony seems to have entered Huberman's 'reassessment' phase, mainly because of the personal crisis of his severe depression and the consequent need to re-evaluate his life. Before his illness, Tony also experimented professionally (although without the stimulus of a change of school), by incorporating grammar within a more task-based approach and making use of self-designed materials. However, since his illness there has in a sense been a regression in Tony's development in that he has reverted to a more conservative, pragmatic, grammar-focused approach which demands less of him and which conforms more closely to the school's exam-focused expectations.

With specific reference to the development of these teachers' subject-matter cognitions, a number of conclusions can be drawn, albeit tentatively given the size of the sample and the limitations of the LA test and the conditions of its administration, as noted above:

(1) It is clearly not the case that years of experience of teaching grammar necessarily lead to expertise. All three teachers have developed in different ways since 1996-97. Maggie is generally a more self-confident teacher, but on the evidence of interview and classroom observation data she still seems to lack confidence in her ability to deal with grammar. Tony, while generally more confident in the classroom, also acknowledges his continuing uncertainties in relation to grammar (' $\mathrm{I}$ 'm still not very confident of what is important, what is more useful to the students' [Interview, 27 May 2004]). Eva has perhaps come closest to the development of a measure of expertise. Although she remains critical of her own handling of grammar and of her ability to elicit the desired response from students, she has nevertheless developed a firm belief in the merits of her overall approach, which showed itself in her classroom performance. However, none of the three reveals anything like the 'rich and integrated knowledge' embedded in the grammar teaching of the expert teacher in Tsui's study (Tsui, 2003: 200).

(2) We noted earlier the uneven nature of teacher professional development generally, with progress in the various dimensions occurring to a different extent and at different rates. From the present study, it seems that the same may be true of teachers' subject-matter cognitions: that some aspects develop more quickly and substantially than others. All three teachers' grammar-related cognitions have evolved in some ways. Both Tony and Maggie, for instance, now have less compartmentalised views of grammar, and an enhanced awareness of the role of grammar in discourse, while Eva and Tony seem to have a broader understanding of the methodological options for dealing with grammar. In the case of Tony and Maggie, these 
developments appear to be the result of their further studies. However, the three teachers' actual knowledge of subject matter (as measured by the LA test) does not seem to have altered at all, arguably because they have not actively sought to develop this aspect of their professional competence through either formal or informal study. Even Maggie's MA in Applied Linguistics did not involve a course specifically focused on grammar. Certainly, the uneven and rather limited evolution of these teachers' subject-matter cognitions is consistent with findings in other studies: that teacher learning in an area is dependent upon a teacher investing time and effort in that specific area and actively searching out related professional challenges (Tsui, 2003), and that those teachers who do not actively seek knowledge do not get it (Borg, 2005).

(3) The third conclusion relates to the importance in teacher development, as shown in the evolution of these teachers' subject-matter cognitions, of the teachers' interaction with context. Huberman (1993) and Tsui (2003), among others, emphasise that context does not impact upon teacher development in a deterministic way. Instead, as Huberman (1993) points out, the process is interactive, with individuals acting on as well as adapting to their social environment. The individual variability of this interactive process is evident in the present study. All three teachers have had to accommodate to some extent to the conditions of their working environment. However, each of them appears to have interacted with their work contexts in different ways. Maggie and Eva, for instance, have both been pro-active in shaping their situational response and in working towards the achievement of a satisfactory compromise between their beliefs about language pedagogy and the constraints of the context. Maggie has achieved this by moving to a more academic and genuinely EMI school and then negotiating for herself a timetable which keeps the need to focus on grammar to a minimum, while Eva is taking advantage of her role as Panel Head to assign herself classes with the most senior forms, where she feels she has the best chance of being able to teach in accordance with her principles. Of the three, it is Tony who has compromised the most - mainly, it would appear, because of his depression. During his sick-leave, he contemplated a change of school. In the end, however, he decided to stay where he was, because it seemed the less stressful option, accepting that by doing so he would have to accommodate to the expectations of the school by making an explicit focus on grammar the core of his teaching.

\section{Correspondence}

Any correspondence should be directed to Dr Stephen Andrews, University of Hong Kong, Faculty of Education, Pokfulam Road, Hong Kong SAR, China (sandrews@hkucc.hku.hk).

\section{Note}

1. An earlier version of this paper was presented at the Association for Language Awareness Conference, Lleida, Spain, July 2004. 


\section{References}

Alderson, J.C., Clapham, C. and Steel, D. (1996) Metalinguistic Knowledge, Language Aptitude and Language Proficiency. CRLE, University of Lancaster Working Papers 26.

Alderson. J.C., Clapham, C. and Steel, D. (1997) Metalinguistic knowledge, language aptitude and language proficiency. Language Teaching Research 1 (2), 93-121.

Andrews, S.J. (1999a) The metalinguistic awareness of Hong Kong secondary school teachers of English. Unpublished PhD thesis, University of Southampton.

Andrews, S.J. (1999b) Why do L2 teachers need to 'know about language'?: Teacher metalinguistic awareness and input for learning. Language and Education 13 (3), 161-77.

Andrews, S.J. (2001) The language awareness of the L2 teacher: Its impact upon pedagogical practice. Language Awareness 10 (2\&3), 75-90.

Andrews, S.J. (2003) Teacher language awareness and the professional knowledge base of the L2 teacher. Language Awareness 12 (2), 81-95.

Andrews, S.J. and McNeill, A. (2005) Knowledge about language and 'good' language teachers. In N. Bartels (ed.) Applied Linguistics and Language Teacher Education (pp. 159-178). Dordrecht: Kluwer.

Berliner, D. (1995) The development of pedagogical expertise. In P.K. Siu and P.T.K. Tam (eds) Quality in Education: Insights from Different Perspectives (pp. 1-14). Hong Kong: Hong Kong Educational Research Association.

Bloor, T. (1986) What do language students know about grammar? British Journal of Language Teaching 24 (3), 157-60.

Borg, S. (1998) Talking about grammar in the foreign language classroom. Language Awareness 7, 159-75.

Borg, S. (2003a) Teacher cognition in language teaching: A review of research on what language teachers think, know, believe and do. Language Teaching 36, 81-109.

Borg. S. (2003b) Teacher cognition in grammar teaching: A literature review. Language Awareness 12 (2), 96-108.

Borg, S. (2005) Experience, knowledge about language and classroom practice in teaching grammar. In N. Bartels (ed.) Applied Linguistics and Language Teacher Education (pp. 325-40). Dordrecht: Kluwer.

Burn, K., Hagger, H., Mutton, T. and Everton, T. (2003) The complex development of student-teachers' thinking. Teachers and Teaching: Theory and Practice 9 (4), 309-31.

Calderhead, J. (1987) The quality of reflection in student teachers' professional learning. European Journal of Teacher Education 10 (3), 269-78.

Farrell, T. (1999) The reflective assignment: Unlocking pre-service teachers' beliefs on grammar teaching. RELC Journal 30, 1-17.

Field, K. (1979) Teacher Development: A Study of the Stages in the Development of Teachers. Brookline, MA: Teacher Center Brookline.

Freeman, D. (2002) The hidden side of the work: Teacher knowledge and learning to teach. Language Teaching 35, 1-13.

Fuller, F. (1969) Concerns of teachers: A development perspective. American Educational Research 6, 207-26.

Fuller, F. and Brown, O.H. (1975) Becoming a teacher. In K. Ryan (ed.) Teacher Education: The Seventy-fourth Yearbook of the National Society for the Study of Education. Chicago: University of Chicago Press.

Furlong, J. and Maynard, T. (1995) Mentoring Student Teachers: The Development of Professional Knowledge. London: Routledge.

Golombek, P.R. and Johnson, K.E. (2004) Narrative inquiry as a mediational space: Examining emotional and cognitive dissonance in second language teachers' development. Teachers and Teaching: Theory and Practice 10 (3), 307-27.

Huberman, M. (1993) The Lives of Teachers. London: Cassell.

Johnson, B. and Goettsch, K. (2000) In search of the knowledge base of language teaching: Explanations by experienced teachers. Canadian Modern Language Review 56, 437-68.

Tsui, A.B.M. (2003) Understanding Expertise in Teaching. Cambridge: Cambridge University Press.

Zhu, J. (2003) The development of pedagogical content knowledge in novice Secondary English teachers in the PRC. Unpublished PhD thesis, University of Hong Kong. 


\section{Appendix 1: Sample Items from the Language Awareness Test Grammar Component}

\section{A. Metalanguage production}

Look at the 12 sentences below. What grammatical terms would you use to describe the item underlined in each of the sentences? Note: For each item provide a full description.

Examples:

1. It was the most exciting film she had ever seen. superlative adjective

2. I saw Jenny last Saturday. verb in past simple tense

\section{B. Grammatical error correction and explanation}

[1 task producing scores for 2 components: Correction of errors, and explanation of errors] This section consists of 15 English sentences, each of which contains a grammar mistake.

For each sentence:

1. Rewrite the faulty part of the sentence correctly. (There is only one part that is wrong.) Do NOT rewrite the whole sentence.

2. Underneath each sentence explain the error.

Example:

I often goes to the cinema.

Correct version: go

Explanation: The verb must agree with the subject

[Do NOT write: Change 'goes' to 'go']

\section{Appendix 2: Specifications for the Participant Narratives}

The instructions for the writing are as follows:

- Write the story of your experience(s) with English grammar, first as a learner, and then as a teacher.

- Write about the development of your feelings and attitudes towards grammar as learner and teacher. Try to mention incidents or situations (inside or outside the classroom, as a learner and a teacher) that you think have influenced you, in your beliefs or your practices.

- Write about your experiences of dealing with grammar as a teacher. Include reflections on your own knowledge about grammar, as well as the teaching of grammar. Try to compare the present 'you' with how you were at the beginning of your career.

- Please be as frank and as specific as you can in describing your experiences.

- Please write fully as you express your feelings and describe your experiences - don't worry about trying to produce a tightly constructed, highly polished piece of narrative.

- When you have written your story, please send it to me as an e-mail attachment. 
- Please try to send me your story within two weeks of the first interview.

- Many thanks!

During the second interview, I shall be particularly interested in comparing the present 'you' with the 'you' I remember from seven years ago. This piece of writing will therefore be very useful input for that interview. 